\title{
Modeling and Dynamic Characteristics of the Dense Phase Region of a Biomass-fired Circulating Fluidized Bed Combustion System Using Modelica
}

\author{
Ya-Ya Liu, ${ }^{a}$ Lei Pan, ${ }^{\mathrm{b}}$ Shan-Jian Liu,,${ }^{\mathrm{a}, *}$ Yong-Jun Li, ${ }^{\mathrm{a}}$ Wei-Dong Liu, ${ }^{\mathrm{a}}$ and \\ Shuai-Chao Wang ${ }^{a}$
}

\begin{abstract}
Using Modelica language, a mathematical model combining static and dynamic contributions of the dense phase region of a $130 \mathrm{t} / \mathrm{h}$ biomass circulating fluidized bed boiler combustion system was established on MWorks simulation platform. The mathematical model adopted modular packaging to increase the universality of the model, and it used an implicit, high-order, and multi-step Dassl integration algorithm to conduct the simulation. Under the design condition parameters, the relative error between the bed temperature of the dense phase region obtained by the simulation model and the actual temperature was less than $3.8 \%$, which indicated that the static characteristics of the established simulation model were accurate. The effects of biomass feed and primary air volume step changes on the bed temperature, oxygen content in the flue gas, height of the dense phase region, and the bed pressure difference in the dense phase region were investigated. Both the biomass feeding and the primary wind step of $10 \%$ reduced the temperature, and it was obvious that the primary wind had a greater impact on the bed temperature. Meanwhile, the primary wind had a greater impact on the bed pressure difference than the biomass feeding.
\end{abstract}

Keywords: Circulating fluidized bed boiler; Dense phase region; Dynamic characteristics; Modelica; Simulation

Contact information: a: Shandong Research Center of Engineering and Technology for Clean Energy, Shandong University of Technology, Zibo, Box 255000, China; b: School of Energy and Environment, Southeast University, Nanjing, Box 210096, China; *Corresponding author: liushanjian08@163.com

\section{INTRODUCTION}

Direct biomass combustion technology is one of the most important ways to utilize biomass for power generation. With the active support and promotion of biomass power generation projects by countries around the world, global biomass power generation has achieved unprecedented development, and the installed capacity of biomass energy has continued to rise steadily. The energy capacity reached 109 GW by 2017 . In 2018, the global installed capacity of biomass energy reached $117 \mathrm{GW}$. In China, the new installed capacity of biomass power generation reached 2.14 million $\mathrm{kW}$ in the first half of 2019, and the cumulative installed capacity reached 19.95 million $\mathrm{kW}$. Biomass is recognized as a renewable energy source for reducing $\mathrm{CO}_{2}$ emissions and conserving natural resources (Bernhardt and Beckmann 2019). Biomass fuels differ in many ways from conventional fossil fuels used in combustion processes, such as coal. They often have high moisture contents, low heating values, and contain a variety of minor chemical constituents, such as chlorine, sulfur, phosphorus, nitrogen, and a variety of ash-forming metals (Mikko et al. 2017). A circulating fluidized bed (CFB) offers several distinct advantages, including wide 
fuel adaptability, high combustion efficiency, low combustion interval temperature, and an easy to realize desulfurization and denitrification process (Chen et al. 2019; Wang et al. 2019). These characteristics of CFB are suitable for biomass burning. However, compared with traditional coal-fired CFB boilers, these special properties of biomass fuels cause several challenges that limit their application for combustion. For example, if small changes in fuel quality occur, this will necessitate changes to the combustion process variables (e.g., bed temperature, bed pressure, oxygen content of the flue gas, etc.). Due to the complexity of the power plant boiler system, the safety requirements of boiler systems are high, and some parameters are difficult to measure directly. It is not easy to study the material flow, heat and mass transfer characteristics in a CFB by changing the working conditions or implementing a start-stop test. Thus, it is particularly important to model the combustion system.

The dense phase region at the bottom of the CFB has a great influence on the hydrodynamic characteristics, heat and mass transfer characteristics, chemical reactions, and pollutant removal efficiency of the whole bed (Gnanapragasam and Reddy 2009). In addition, specific factors, including a stable bed temperature in the dense phase region and the transportation of the bed materials, are particularly important to maintain the stable operation of the whole boiler system. Therefore, studying the dynamic characteristics of the dense phase region of the CFB in the event of disruptive working conditions can help to ensure the safe and stable operation of the CFB unit.

At present, there are many studies that have been conducted concerning the combustion system of coal-fired CFB boilers. However, there are few studies focusing on the CFB combustion of burning pure biomass. In addition, a large number of mathematical models, including CFD models and dynamic simulation models (Lu et al. 2013; Wang et al. 2013; Koksharev et al. 2017), have been developed to study the overall performance of CFB boilers in the past few years. Due to the limitation of computing power, it takes a lot of time to use the CFD method to conduct transient simulations. Moreover, it is difficult to solve the model quickly, it is difficult to obtain the dynamic response of the whole system in a short time (Wu et al. 2018), and the established simulation model can be inherited poorly. Modelica is an object-oriented, structural, and mathematical modeling language based on non-causal modeling. This modeling language has multi-domain, unified, noncausal statement, and continuous/discrete hybrid modeling capabilities, resulting in flexible, efficient modeling, and high model reusability. In addition, Modelica is open-source, scalable, and more accurate than other similar modeling languages, and it is efficient for complex physical modeling (Alobaid et al. 2017; Qin et al. 2019). In recent years, Modelica has been widely used in a vast array of mechanical, electrical, energy, and chemical fields, leading to the production and dissemination of fruitful research results (Maccarini et al. 2017; Ceraolo and Lutzemberger 2019; Ploch et al. 2019). Therefore, this paper established a mathematical model combining static and dynamic contributions of the dense phase region of a $130 \mathrm{t} / \mathrm{h}$ boiler combustion system on the MWorks simulation platform with Modelica language. Moreover, this study also conducted a simulation test study on major output parameters (e.g., bed temperature, bed pressure difference, and oxygen content of the flue gas) in the dense phase region through fuel feeding and primary air step changes. 


\section{MODELING AND NUMERICAL SIMULATION}

\section{Physical Object}

The dense phase region of the combustion system of a certain power plant biomassfired CFB boiler (Jinan Boiler Group Co., Ltd., Jinan, China) was modeled. The structure diagram of the CFB boiler is shown in Fig. 1.

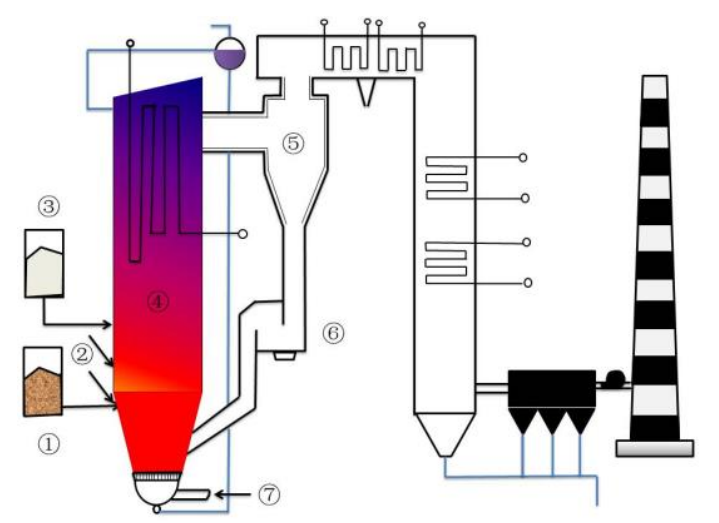

Fig. 1. The system schematic of a biomass-fired boiler combustion system power plant: 1. Biomass material; 2. Secondary air; 3. Limestone (reserved); 4. Furnace; 5. Cyclone; 6. Loop-seal; 7. Primary air

The combustion system of the power plant is mainly composed of feed inlet, furnace, cyclone, U-shaped loop-seal, primary air and secondary air. The primary air is the fluidized air, which provides air for fuel combustion in the dense phase zone, and the secondary air provides air for further combustion of the fuel. In order to prevent ash corrosion of the heat exchange surface, the heat exchange equipment was arranged separately in the flue. The design of this furnace has reserved limestone inlet. If the concentration of $\mathrm{SO}_{2}$ emissions exceeds local standards (35 to $100 \mathrm{mg} / \mathrm{Nm}^{3}$, Shandong province, China) in operation, limestone will be added into the boiler. The main dimensions and design operating parameters of the biomass-fired CFB boiler are shown in Table 1.

Table 1. Furnace Size and Operating Parameters

\begin{tabular}{|c|c|c|c|}
\hline $\begin{array}{c}\text { Design Operation } \\
\text { Parameters }\end{array}$ & Value & Design Operation Parameters & Value \\
\hline Width of the Furnace & $8760 \mathrm{~mm}$ & Fuel particle size & 0 to $100 \mathrm{~mm}$ \\
\hline Depth of the Furnace & $5400 \mathrm{~mm}$ & Bed material size & 0 to $2 \mathrm{~mm}$ \\
\hline Height of the Furnace & $30000 \mathrm{~mm}$ & Excess air ratio & 1.2 \\
\hline Distributor Area & $7.14 \mathrm{~m}^{2}$ & Primary air volume & $101974 \mathrm{~m}^{3} / \mathrm{h}$ \\
\hline Biomass Feeding & $35.286 \mathrm{t} / \mathrm{h}$ & Boiler max. continuous rating (BMCR) & $143 \mathrm{t} / \mathrm{h}$ \\
\hline Bed Temperature & $785^{\circ} \mathrm{C}$ & & \\
\hline
\end{tabular}

The combustion model of the dense phase region in a biomass-fired CFB mainly includes a flow model, coke combustion model, heat transfer coefficient, and other submodels. The mathematical model of the dense phase region was established by combining 
mass conservation and energy conservation equations. To facilitate modeling and reduce the number of differential equations that need to be solved, the mathematical model of the dense phase region was reasonably simplified, and the following assumptions were made:

(1) The combustor was divided into two different regions along the height of the furnace, dense phase region and dilute phase region. The interface between the dense phase region and the thin phase region was assumed to be the height of the dense phase region.

(2) For the dense phase region, the uneven flow structure in the furnace was ignored and subsequently treated as a symmetrical structure. The annular-nuclear structure of the dense phase flow was ignored, which signified that the radius was assumed to be uniform.

(3) Each material was simplified to a single particle size. The solid particle shape was assumed to be spherical, and each material was represented by an average particle size. The size of the biomass particle did not change during the combustion process.

\section{Mathematical Model of the Flow}

The hydrodynamic characteristics determine the operating wind speed, the limits at variable operating conditions, the energy consumption of the auxiliary machine, the heat transfer in the bed, the temperature distribution, the amount of material in the bed, and the wear of the heating surface in the CFB. Therefore, the study of gas-solid two-phase fluid dynamics is the basis of heat and mass transfer in the CFB.

The height of the dense phase bed is the key quantity to divide the dense phase region and thin phase region. To determine the height of the dense phase bed, the flow parameters should first be determined. The calculation formula of $d_{\mathrm{B}}$ is as follows (Bergougnou et al. 1986),

$$
d_{\mathrm{B}}=\frac{0.54}{g^{0.2}}\left(U_{0}-U_{\mathrm{mf}}\right)^{0.4}\left(h_{\mathrm{den}}+4 \sqrt{\frac{A_{\mathrm{B}}}{N_{\text {nos }}}}\right)^{0.8}
$$

where, $d_{\mathrm{B}}$ is average diameter of bubbles at the interface of the dense phase region $(\mathrm{m}), g$ is gravitational constant, $g=9.81\left(\mathrm{~m} \cdot \mathrm{s}^{-2}\right), U_{0}$ is apparent velocity $\left(\mathrm{m} \cdot \mathrm{s}^{-1}\right), h_{\text {den }}$ is dense phase region height $(\mathrm{m}), A_{\mathrm{B}}$ is cross-sectional area of the furnace $\left(\mathrm{m}^{2}\right), N_{\text {nos }}$ is number of nozzles for the air distribution plate, $U_{\mathrm{mf}}$ is the minimum fluidization velocity $\left(\mathrm{m} \cdot \mathrm{s}^{-1}\right)$, and the calculation formula is as follows (Wen et al. 1966):

$$
U_{\mathrm{mf}}=0.249 \frac{d_{\mathrm{p}}^{0.584}}{\vartheta_{\mathrm{g}}^{0.056}}\left(\frac{\rho_{\mathrm{p}}-\rho_{\mathrm{g}}}{\rho_{\mathrm{g}}}\right)^{0.528}
$$

Then, $h_{\mathrm{den}}$ is calculated as follows:

$$
\begin{aligned}
& h_{\mathrm{den}}=R_{\mathrm{den}} \times h_{\mathrm{den}}^{0} \\
& h_{\mathrm{den}}^{0}=\frac{M_{\mathrm{p}}}{A_{\mathrm{B}} \rho_{p}} \\
& R_{\mathrm{den}}=1-\frac{Y\left(U_{0}-U_{\mathrm{mf}}\right)}{U_{\mathrm{B}}} \\
& Y=\frac{Q_{b} / A_{B}}{\left(u_{0}-u_{\mathrm{mf}}\right)}
\end{aligned}
$$

where, $d_{\mathrm{p}}$ is bed material mean particle diameter $(\mathrm{m}), \rho_{\mathrm{p}}$ is bed material particle density $\left(\mathrm{kg} \cdot \mathrm{m}^{3}\right), \rho_{\mathrm{g}}$ is gas phase density $\left(\mathrm{kg} \cdot \mathrm{m}^{3}\right), \vartheta_{\mathrm{g}}$ is kinematic viscosity $\left(\mathrm{m}^{2} \cdot \mathrm{s}^{-1}\right), h_{\text {den }}^{0}$ is static bed material layer height $(\mathrm{m}), M_{\mathrm{p}}$ is mass of solid particles in the dense phase $(\mathrm{kg}), R_{\mathrm{den}}$ is expansion ratio, $Q_{b}$ is volume flow rate of bubbles $\left(\mathrm{m}^{3} \cdot \mathrm{s}^{-1}\right)$, and $Y$ is the ratio of the flow 
rate of visible bubbles to the flow rate of bubbles according to two-phase flow theory. For a Geldart B particle, $Y$ is 0.67 (Geldart and Baeyens 1985).

The bubble flow velocity $U_{\mathrm{B}}$ is calculated using the formula suggested by Kunni and Levenspiel (Kunii and Levenspiel 1990):

$$
U_{\mathrm{B}}=0.71 \sqrt{g d_{\mathrm{B}}}+\left(U_{0}-U_{\mathrm{mf}}\right)
$$

The surface entrapment of the dense phase region is the mass flow rate brought into the thin phase region by the bubble rupture when the bubble flows from the inside of the dense phase region to the interface of the dense phase region. The calculation formula for the surface entrainment rate in the dense phase region is calculated as follows (Wen and Chen 1982):

$$
E_{0}=3.07 \times 10^{-9} \rho_{\mathrm{g}}{ }^{3.5}\left(\frac{U_{0}-U_{\mathrm{mf}}}{\mu_{\mathrm{g}}}\right)^{2.5} A_{\mathrm{B}} d_{\mathrm{B}}
$$

where $\mu_{\mathrm{g}}$ is dynamic viscosity of gas $(\mathrm{Pa} \cdot \mathrm{s})$.

\section{Coke Combustion Sub-model}

The coke combustion model is used to determine the residual carbon content in the furnace, the percentage of the flue gas composition, and the coke reaction rate. The coke combustion occurs on the outer surface of the coke particles. The $\mathrm{CO}$ and $\mathrm{CO}_{2}$ are both primary products of coke combustion, and there is a concentration gradient between them. The combustion rate of coke is jointly controlled by the chemical reaction rate and the gas diffusion rate. The reaction of coke is based on the following model (Xiao et al. 2009):

$$
\begin{array}{lc}
\Phi \mathrm{C}+\mathrm{O}_{2} \rightarrow 2(\Phi-1) \mathrm{CO}+(2-\Phi) \mathrm{CO}_{2} \\
\Phi=\frac{2 p+2}{p+2} & d_{c} \leq 0.05 \mathrm{~mm} \\
\Phi=\frac{2 p+2-\frac{p}{0.095}\left(100 d_{\mathrm{c}}-0.005\right)}{p+2} & 0.05 \mathrm{~mm}<d_{c} \leq 1 \mathrm{~mm} \\
\Phi=1 & 1.0 \mathrm{~mm}<d_{\mathrm{c}} \\
p=2500 \exp \left[-\frac{5.19 \times 10^{4}}{R T_{\mathrm{c}}}\right] & \\
T_{\mathrm{c}}=T_{\mathrm{B}}+66 C_{\mathrm{O}_{2}} &
\end{array}
$$

where, $\Phi$ is chemical reaction mechanical factor, $d_{c}$ is coke particle diameter $(\mathrm{m}), T_{\mathrm{c}}$ is the Surface temperature of coke particles $(\mathrm{K}), T_{\mathrm{B}}$ is bed temperature $(\mathrm{K}), C_{\mathrm{O}_{2}}$ is molar concentration of oxygen $\left(\mathrm{mol} \cdot \mathrm{m}^{-3}\right)$.

The combustion rate of coke is related to the oxygen content, carbon mass in the bed, and the reaction temperature. For a single coke particle, the combustion rate $r_{\mathrm{c}}$ is:

$$
\begin{aligned}
& r_{\mathrm{c}}=12 \pi d_{\mathrm{c}}^{2} K_{\mathrm{c}} C_{\mathrm{O}_{2}} \\
& C_{\mathrm{O}_{2}}=\frac{\mathrm{P}_{\mathrm{O}_{2}}}{\mathrm{RT}_{\mathrm{B}}} Y_{\mathrm{O}_{2}}
\end{aligned}
$$

From Eq. 15 and Eq. 16, the following set of equations can be deduced:

$$
r_{\mathrm{c}}=12 \pi d_{\mathrm{c}}^{2} K_{\mathrm{c}} \frac{P_{\mathrm{O}_{2}}}{R T_{\mathrm{b}}} Y_{\mathrm{O}_{2}}
$$




$$
P_{\mathrm{O}_{2}}=X_{\mathrm{O}_{2}} \times P
$$

The reaction rate of coke particles $K_{c}$ is calculated by the following formula (Wu et al. 2018):

$$
\begin{aligned}
& K_{\mathrm{c}}=\frac{1}{\frac{1}{\phi K_{\mathrm{d}}}+\frac{1}{K_{\mathrm{s}}}} \\
& K_{\mathrm{d}}=\frac{s h D_{\mathrm{g}}}{d_{\mathrm{c}}} \\
& s h=2.0+0.69 R e_{\mathrm{T}}^{0.5} S c^{0.33} \\
& R e_{\mathrm{T}}=\frac{A r \varepsilon^{4.75}}{18+0.61\left(A r \varepsilon^{4.74}\right)^{0.5}} \\
& S c=\frac{\mu_{\mathrm{g}}}{\rho_{\mathrm{g}} D_{\mathrm{g}}} \\
& D_{\mathrm{g}}(T, P)=D_{\mathrm{g}}\left(T_{0}, P_{0}\right)\left[\frac{T}{T_{0}}\right]^{1.75}\left[\frac{P_{0}}{P}\right]
\end{aligned}
$$

In Eq. 24, $D_{\mathrm{g}}\left(T_{0}, P_{0}\right)$ is the diffusion coefficient with a reference temperature $T_{0}$ and reference pressure $P_{0}$.

The surface chemical reaction rate is determined by the type of carbon and the surface temperature, and the expression for this equation can be expressed as follows:

$$
K_{\mathrm{s}}=K_{0 \mathrm{~s}} T_{\mathrm{M}} \exp \left[-\frac{E_{\mathrm{c}}}{R T_{\mathrm{c}}}\right]
$$
formula:

Then, total coke combustion reaction rate $W_{\mathrm{RC}}$ is calculated by the following

$$
W_{\mathrm{RC}}=\frac{72 M_{\mathrm{c}}}{d_{\mathrm{c}} \rho_{\mathrm{c}}} \frac{P}{R T_{\mathrm{b}}} k_{\mathrm{c}} Y_{\mathrm{O}_{2}}
$$

\section{Heat Transfer Sub-model}

Due to the strong mixing of substances in a CFB, the heat balance between bubbles and particles, and the balance between particles and particles can be instantly reached. Generally, only the heat transfer between the bed layer and the wall surface was considered. The heat transfer coefficient between the fluidized bed and the heating surface is usually divided into three parts:

$$
h=h_{\mathrm{gc}}+h_{\mathrm{pc}}+h_{\mathrm{rad}}
$$

(1) Convection heat transfer coefficient of the gas:

The airflow in the dense phase region was enveloped by the bed particles. The convective heat transfer of gas was obvious only when the particle concentration was low. Therefore, the convective heat transfer of gas occupied a small proportion of the CFB. The heat transfer coefficient of gas convection was calculated from the following formula (Martin 1984):

$$
\begin{aligned}
& h_{\mathrm{gc}}=0.009 \frac{\lambda_{\mathrm{g}}}{d_{\mathrm{p}}} \operatorname{Pr}^{1 / 3} A r^{1 / 2} \\
& \operatorname{Pr}=\frac{C_{\mathrm{pg}} \mu_{\mathrm{g}}}{\lambda_{\mathrm{g}}}
\end{aligned}
$$




$$
\begin{aligned}
& A r=\frac{\rho_{\mathrm{g}}\left(\rho_{\mathrm{p}}-\rho_{\mathrm{g}}\right) g d_{\mathrm{p}}^{3}}{\mu_{\mathrm{g}}^{2}} \\
& \lambda_{\mathrm{g}}=0.02284+0.8445 \times 10^{-4}(T-273)+0.1735 \times 10^{-8}(T-273)^{2}
\end{aligned}
$$

where $\mathrm{Pr}$ is Prandtl number, $A r$ is Archimedes number, and $T$ is the flue gas temperature (K).

(2) Convective heat transfer coefficient of particles:

The particle concentration within the CFB dense-phase region was high. The temperature in this region was lower than that in the dilute phase region, so the particle convection heat transfer was only considered in the dense phase region. At the same time, the contact area between particle groups and the wall surface was small, and the space between the particles and the wall was full of the gas, so the influence of the gas contacting the wall should be considered when constructing the particle convection heat transfer model (Eckert and Martin 1972). In Eqs. 32 through 34,

$$
\begin{aligned}
& h_{\mathrm{pc}}=\frac{\lambda_{\mathrm{g}}}{d_{\mathrm{p}}}(1-\varepsilon) Z\left[1-e^{-\mathrm{N}}\right] \\
& Z=\frac{\rho_{\mathrm{p}} C_{\mathrm{p}}}{6 \lambda_{\mathrm{g}}} \sqrt{\frac{g d_{\mathrm{p}}^{3}\left(\varepsilon-\varepsilon_{\mathrm{mf}}\right)}{5\left(1-\varepsilon_{\mathrm{mf}}\right)(1-\varepsilon)}} \\
& N=\frac{4\left[\left(1+\frac{2 \sigma}{d_{\mathrm{p}}}\right) \ln \left(1+\frac{d_{\mathrm{p}}}{2 \sigma}\right)-1\right]}{C_{\mathrm{K}} Z}
\end{aligned}
$$

$\varepsilon$ is void fraction, $\varepsilon_{\mathrm{mf}}$ is critical voidage of fluidized bed, and $\sigma$ is free path of gas molecule.

(3) Radiant heat transfer coefficient:

Radiative heat transfer mainly occurs between high-temperature particles and heating surfaces. Radiative heat transfer in a CFB is related to the temperature of the heating surface, particle density of the bed, the temperature of the bed, and other physical quantities (Basu 1990). In Eq. 35,

$$
h_{\mathrm{rad}}=\frac{\sigma\left(T_{\mathrm{B}}^{4}-T_{\mathrm{W}}^{4}\right)}{\left(\frac{1}{\varepsilon_{\mathrm{b}}}+\frac{1}{\varepsilon_{\mathrm{W}}}-1\right)\left(T_{\mathrm{B}}-T_{\mathrm{W}}\right)}
$$

$\sigma$ is Boltzmann constant, the value is $5.672 \times 10^{-8}\left(\mathrm{~W} \cdot \mathrm{m}^{-2} \cdot \mathrm{K}^{-4}\right)$.

\section{Mass and Energy Balance Equation Model}

The material balance in the dense phase region plays an important role in maintaining the normal operation of the boiler. The temperature and the pressure of the bed are imperative to maintaining the stable combustion within the boiler.

The dynamic mass balance equation of coke (Fig. 2a) is given by Eq. 36,

$$
\frac{d M_{\mathrm{C}}}{d \tau}=\frac{W_{\mathrm{Fuel}} F_{\mathrm{Car}}}{100}+W_{\mathrm{C} 2-1}+W_{\mathrm{CO}-1}-W_{\mathrm{C} 1-2}-W_{\mathrm{dC}}-W_{\mathrm{Cr}}
$$

where $M_{\mathrm{c}}$ is accumulation mass of coke in the dense phase region $(\mathrm{kg}), W_{\text {Fuel }}$ is biomass fuel feed rate $\left(\mathrm{kg} \cdot \mathrm{s}^{-1}\right), F_{\mathrm{Car}}$ is fixed carbon content of as received basis, $W_{\mathrm{C} 2-1}$ is coke flow from the dilute phase region into the dense phase region $\left(\mathrm{kg} \cdot \mathrm{s}^{-1}\right), W_{\mathrm{CO}-1}$ is coke flow from the loop-seal into the dense phase region $\left(\mathrm{kg} \cdot \mathrm{s}^{-1}\right), W_{\mathrm{C} 1-2}$ is coke flow from dense phase 
region into the dilute phase region $\left(\mathrm{kg} \cdot \mathrm{s}^{-1}\right), W_{\mathrm{dC}}$ is coke flow taken away by slag removal $\left(\mathrm{kg} \cdot \mathrm{s}^{-1}\right)$, and $W_{\mathrm{Cr}}$ is Coke combustion consumption $\left(\mathrm{kg} \cdot \mathrm{s}^{-1}\right)$.

The dynamic mass balance equation of bed material particles (Fig. 2b) is given by Eq. 37,

$$
\frac{d M_{\mathrm{p}}}{d \tau}=W_{\text {Fuel }}+W_{\text {pori }}+\frac{W_{\mathrm{Cr}}}{A_{\mathrm{ar}}} \times 100+W_{\mathrm{p} 2-1}+W_{\mathrm{pO}-1}-W_{\mathrm{p} 1-2}-W_{\mathrm{dash}}-W_{\mathrm{Cr}}
$$

where $W_{\text {pori }}$ is bed materials addition amount $\left(\mathrm{kg} \cdot \mathrm{s}^{-1}\right), A_{\mathrm{ar}}$ is Ash content of as received basis, $W_{\mathrm{p} 2-1}$ is bed material amounts flowing from the dilute phase region into the dense phase region $\left(\mathrm{kg} \cdot \mathrm{s}^{-1}\right), W_{\mathrm{pO}-1}$ is bed material amounts flowing from the loop-seal into the dense phase region $\left(\mathrm{kg} \cdot \mathrm{s}^{-1}\right), W_{\mathrm{p} 1-2}$ is bed material amounts flowing from the dense phase region into the dilute phase region $\left(\mathrm{kg} \cdot \mathrm{s}^{-1}\right)$, and $W_{\text {dash }}$ is bed material flow taken away by slag removal $\left(\mathrm{kg} \cdot \mathrm{s}^{-1}\right)$.

Energy conservation equation (Fig. 2c):

$\frac{d\left(M_{\mathrm{p}} H_{\mathrm{p}}+M_{\mathrm{gas}} H_{\mathrm{gas}}\right)}{d \tau}=Q_{\mathrm{Fuel}}+Q_{\mathrm{air}}+Q_{\mathrm{o}-1}+Q-Q_{\mathrm{gy}}-Q_{\mathrm{e}}-Q_{\mathrm{dash}}-Q_{\mathrm{exc}}$

where $H_{\mathrm{p}}$ is specific enthalpy of bed material $(\mathrm{J} / \mathrm{kg}), H_{\text {gas }}$ is specific enthalpy of gas $(\mathrm{J} / \mathrm{kg})$, $Q_{\text {Fuel }}$ is heat that biomass fuel brings into the dense phase region $\left(\mathrm{J} \cdot \mathrm{s}^{-1}\right), Q_{\text {air }}$ is heat that air brings into the dense phase region $\left(\mathrm{J} \cdot \mathrm{s}^{-1}\right), Q_{\mathrm{o}-1}$ is heat that is brought into the dense phase region from loop-seal $\left(\mathrm{J} \cdot \mathrm{s}^{-1}\right), Q$ is heat released by biomass combustion, $Q_{\mathrm{gy}}$ is heat taken away by the flue gas $\left(\mathrm{J} \cdot \mathrm{s}^{-1}\right), Q_{\mathrm{e}}$ is heat that brought into the dilute phase region from the dense phase region $\left(\mathrm{J} \cdot \mathrm{s}^{-1}\right), Q_{\text {dash }}$ is heat taken away by slag $\left(\mathrm{J} \cdot \mathrm{s}^{-1}\right), Q_{\text {exc }}$ is heat exchanged between the bed and the heated surface $\left(\mathrm{J} \cdot \mathrm{s}^{-1}\right)$.

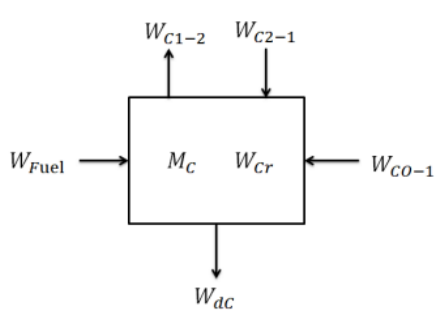

(a) Diagram of coke mass flow

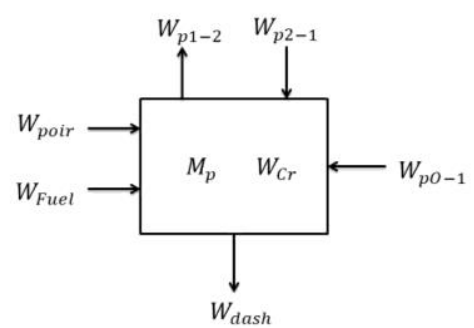

(b) Diagram of the mass flow

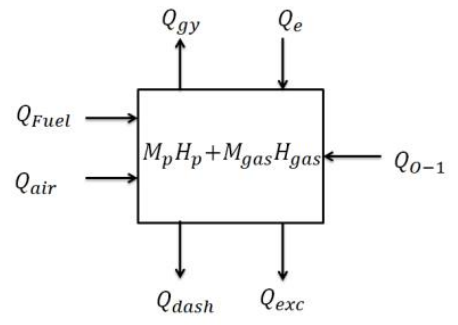

(c) Diagram of the furnace energy flow

Fig. 2. Diagram of coke mass flow, the mass flow, and the furnace energy flow in the dense phase region

Because the gas reaction is a rapid process, the gas reaction is simplified to a static model, thus, it is assumed that there is no gas accumulation in the dense phase region. Therefore, Eq. 38 can be rewritten as follows:

$$
\frac{d T_{\mathrm{B}}}{d \tau} M_{\mathrm{p}} c_{\mathrm{p}}=Q_{\mathrm{Fuel}}+Q_{\mathrm{air}}+Q_{\mathrm{o}-1}+Q-Q_{\mathrm{gy}}-Q_{\mathrm{e}}-Q_{\mathrm{dash}}-Q_{\mathrm{exc}}
$$

Based on the Modelica modeling language, a mathematical simulation model was built on the Mworks software platform (Suzhou Tongyuan Soft. \& Tech. Co., Ltd., v.4.1.3.2118, Suzhou, China) for the dense phase region of the power plant biomass-fired CFB boiler. A modular package was adopted to increase the universality of the model. The structure diagram after implementation of the package is shown in Fig. 3. 


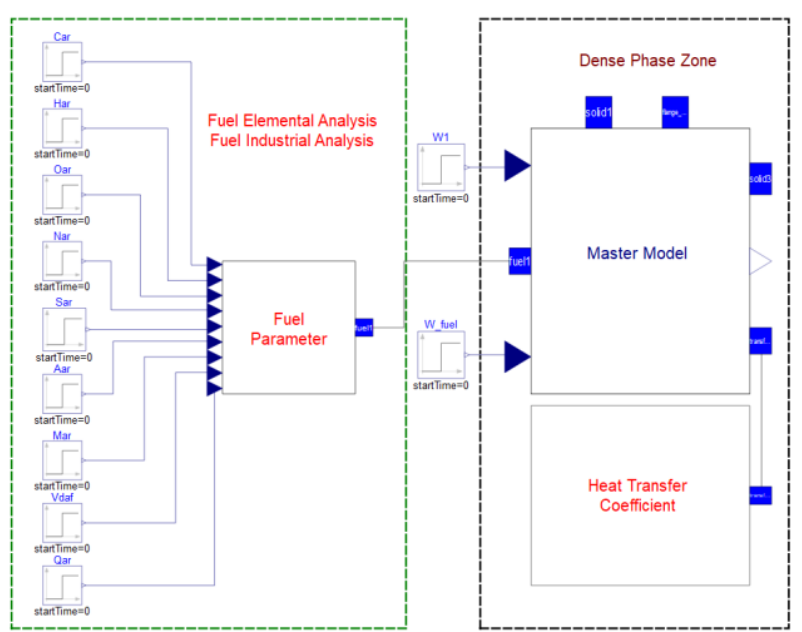

Fig. 3. Simulation model of the dense phase region of the CFB system after encapsulation

\section{RESULTS AND DISCUSSION}

After establishing the simulation model based on the above mathematical models, the simulation model was initialized and debugged. The Dassl integral algorithm, an implicit, high order, multi-step, and stable algorithm for solving the model, was used during the simulation experiment.

Table 2. Proximate and Elemental Analysis Results of the Fuels (as Received)

\begin{tabular}{|c|c|c|c|c|c|c|c|c|c|c|}
\hline \multicolumn{4}{|c|}{ Proximate Analysis (Mass Fraction, \%) } & \multicolumn{6}{|c|}{$\begin{array}{l}\text { Elemental Analysis } \\
\text { (Mass Fraction, \%) }\end{array}$} & \multirow{2}{*}{$\begin{array}{c}\text { Lower } \\
\text { Calorific } \\
\text { Value } \\
(\mathrm{kJ} / \mathrm{kg})\end{array}$} \\
\hline Moi & $\begin{array}{c}\text { Ash } \\
\text { content }\end{array}$ & $\begin{array}{l}\text { Volatile } \\
\text { matter }\end{array}$ & $\begin{array}{l}\text { Fixed } \\
\text { carbon }\end{array}$ & $\mathrm{Nar}$ & Car & $\mathrm{Har}_{\mathrm{ar}}$ & Sar & $\mathrm{Oar}$ & Clar & \\
\hline 40 & 1.32 & 45. & 13.47 & 0.17 & 31.32 & 3.45 & $\begin{array}{c}0.0 \\
1\end{array}$ & $\begin{array}{c}23.7 \\
2 \\
\end{array}$ & $\begin{array}{c}0.0 \\
8\end{array}$ & 60 \\
\hline
\end{tabular}

The mixed fuel $(40 \%$ bark $+30 \%$ wood chips $+20 \%$ firewood $+5 \%$ wheat straw + $5 \%$ corn straw) of the site was bark, wood chips, firewood, wheat straw, corn straw, and other wood processing residues. The bark, sawdust, and "firewood" were the mainly wood residues (e.g., pine, cypress, birch, etc.) from the production of hardwood furniture. Proximate analysis and ultimate analysis results of the feedstock are displayed in Table 2.

\section{Verification of the Initialized Simulation Results}

For the initialization of the simulation model, the biomass feed was $9.8 \mathrm{~kg} / \mathrm{s}$, and the primary air flow was $28.3 \mathrm{~m}^{3} / \mathrm{s}$. The simulation results in the dense phase region are shown in Fig. 4. The steady state temperature of the dense phase region (Fig. 4a) was $827^{\circ} \mathrm{C}$. The relative error between the steady state temperature and the designed operating temperature of the bed $\left(785^{\circ} \mathrm{C}\right)$ was no more than $3.8 \%$, indicating that the static characteristics of the established simulation model were relatively accurate, which verified the reliability of the model. 

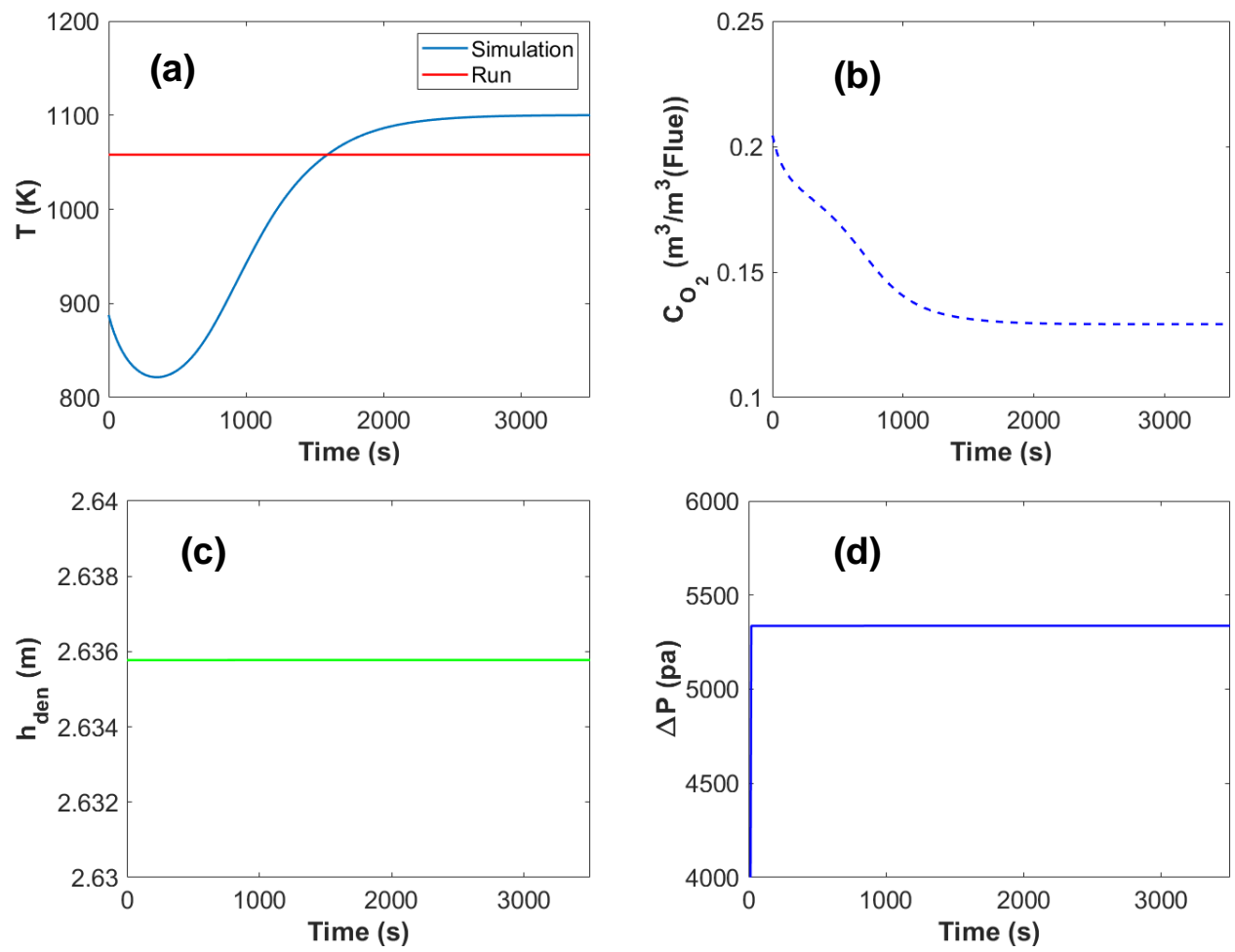

Fig. 4. Simulation results with initial parameters: (a) Bed temperature of the dense phase region; (b) oxygen concentration in dense phase zone; (c) The height of the dense phase region; (d) bed pressure difference in the dense phase region

In Fig. 4, under the BMCR condition, the oxygen concentration (b) in dense phase zone was approximately $12.8 \%$, which indicated that the dense phase region was not the primary combustion zone for the biomass fuel. Some researchers (Gungor 2008; Zhong et al. 2015) also pointed out that the combustion of biomass in a circulating fluidized bed was mainly concentrated in the upper part of the dense phase region, which further verified the accuracy of the model. The height of the dense phase region (c) was $2.636 \mathrm{~m}$. It can be seen that the bed pressure difference (d) in the dense phase region reached $5337 \mathrm{~Pa}$, indicating that the wind resistance in the dense phase zone was relatively large.

\section{Dynamic Simulation Test in the Dense Phase Region}

After the system reached steady state, the remaining parameters remained unchanged, and the amount of biomass added was increased $10 \%$, from $9.8 \mathrm{~kg} / \mathrm{s}$ to 10.78 $\mathrm{kg} / \mathrm{s}$ at $2000 \mathrm{~s}$. At this time, the response curves in the dense phase region were calculated. The results of this simulation are shown in Fig. 5. 

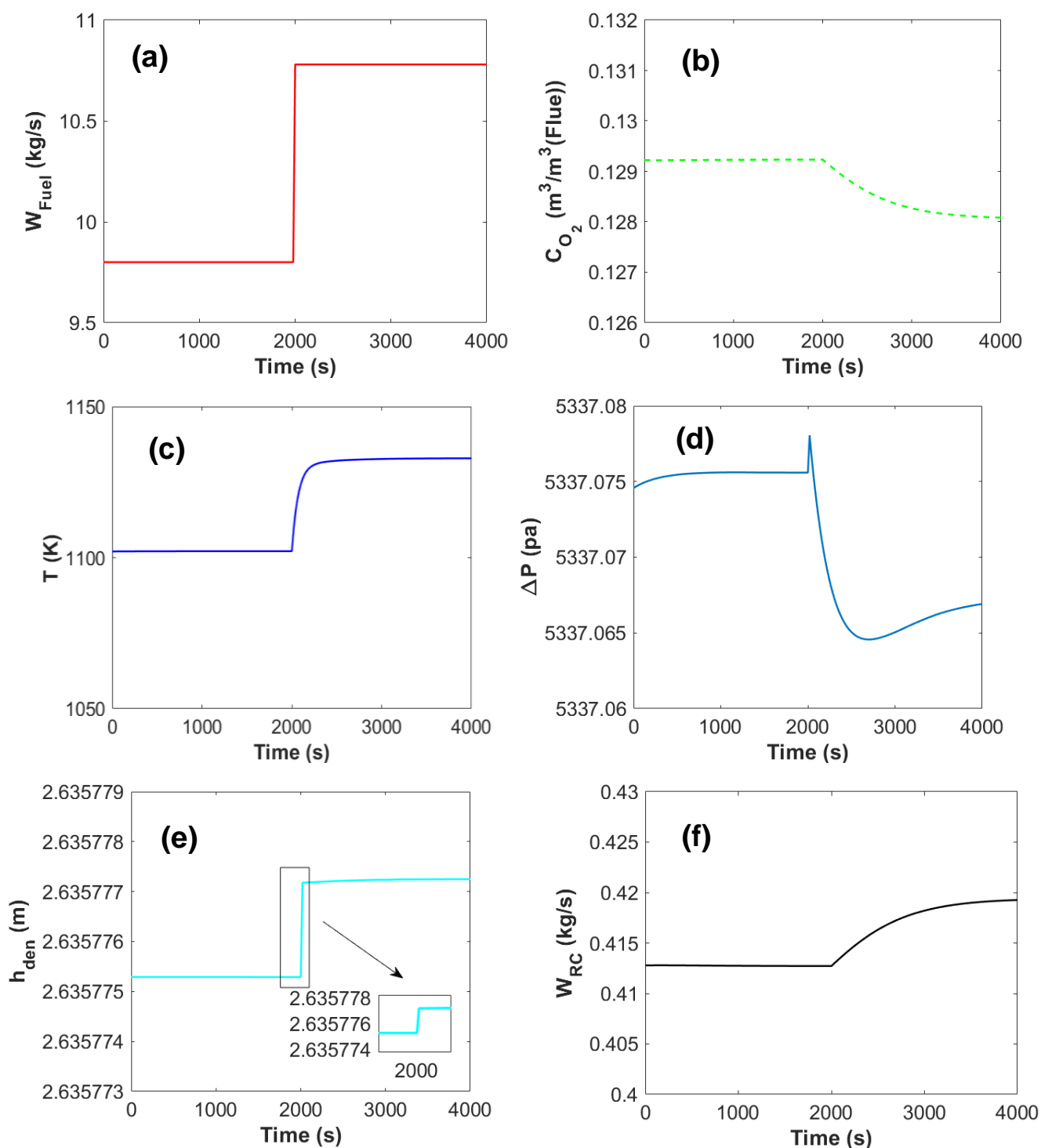

Fig. 5. Dynamic response curve in the dense phase region when the biomass feed step was changed: (a) Biomass feeding step; (b) Oxygen concentration in the dense phase zone; (c) Temperature in the dense phase region; (d) Bed pressure difference; (e) Height of the dense phase region; and (f) combustion rate of coke

As shown in Fig. 5, when the biomass feeding was increased 10\%, the oxygen concentration in the dense phase zone slowly decreased to $12.8 \%$ (Fig. 5b). This signified that increasing the amount of biomass promoted the combustion of the fuel. The temperature in the dense phase region increased slightly and then gradually reached a new equilibrium value (Fig. 5c). This can be explained by the fact that an increase of the biomass content can promote the combustion of the biomass fuel. From Fig. 5d and Fig. 5e, it can be seen that the increase of the biomass fuel had little impact on the bed pressure difference and the height of the dense phase region. Meanwhile, the combustion rate of coke increased slowly (Fig. 5f).

It is worth noting that the bed height and pressure difference in the dense phase zone are related to the amount of bed material in the dense phase zone. However, due to the low fixed carbon content of biomass fuel, sand needs to be added as a bed material. Compared to a lot of bed material, the increase of biomass promoted the rate of biomass combustion, 
which had an impact on the bed temperature and the oxygen concentration in the dense phase zone, while the slight combustion of biomass-fixed carbon has a negligible effect on the bed material. Therefore, the bed height and bed pressure difference in the dense phase zone changed instantaneously at $2000 \mathrm{~s}$.
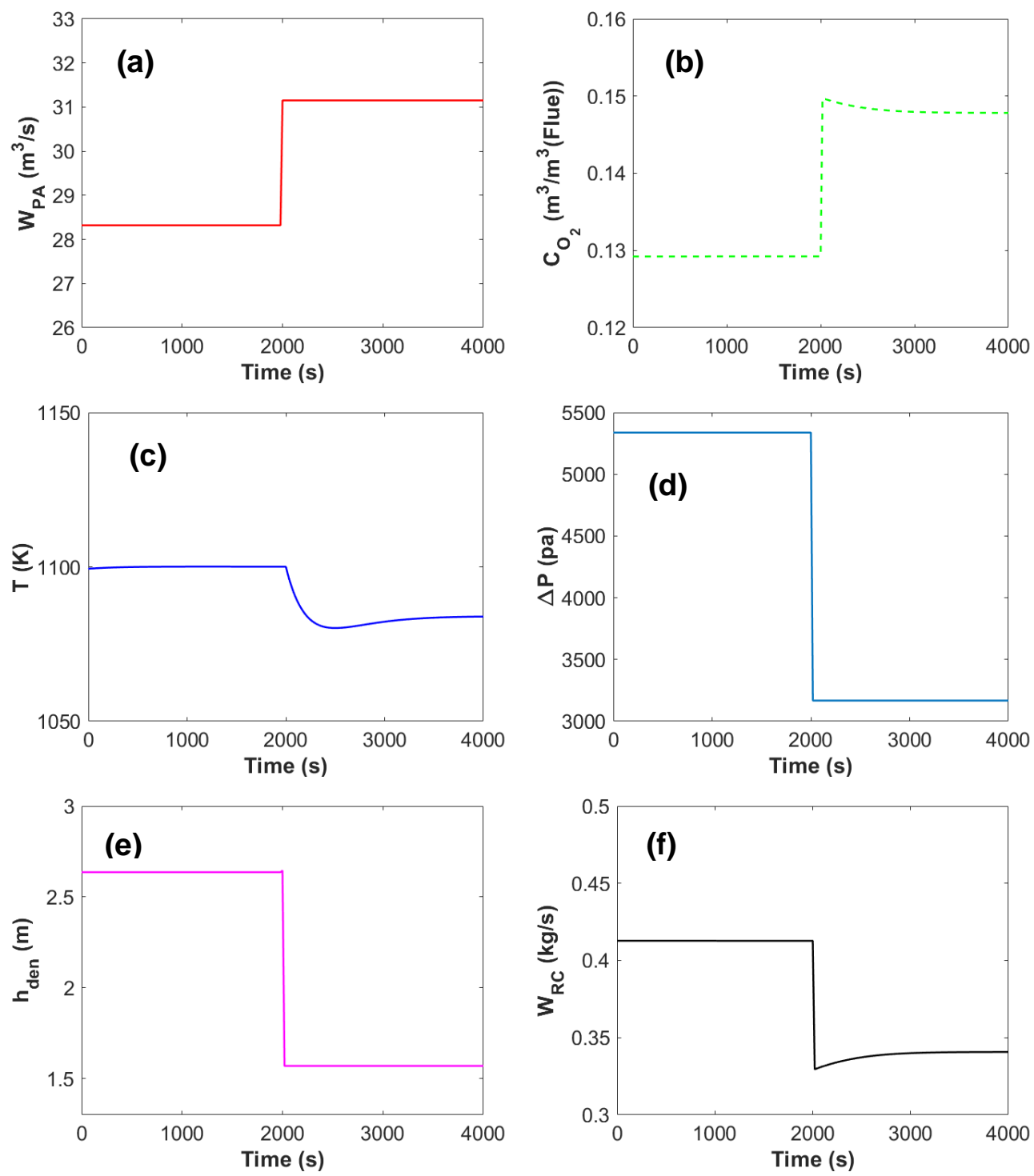

Fig. 6. Dynamic response curve in the dense phase region when the primary air step changed: (a) Primary air step (b) Oxygen concentration in the dense phase zone (c) Temperature in the dense phase region (d) Bed pressure difference (e) Height of the dense phase region (f) combustion rate of coke 
After the system reached steady state, the remaining parameters were unchanged, and the primary air volume was increased $10 \%$, from $28.3 \mathrm{~m}^{3} / \mathrm{s}$ to $31.1 \mathrm{~m}^{3} / \mathrm{s}$ at $2000 \mathrm{~s}$. At this time, the response curves in the dense phase region were calculated. The results of this simulation are shown in Fig. 6.

As shown in Fig. 6, when the primary air was increased 10\%, the oxygen concentration in the dense phase region rapidly increased to $15 \%$ and then decreased slowly to $14.5 \%$. This signified that increasing the amount of the primary air brought in more oxygen and promoted the combustion of the fuel. The temperature in the dense phase region decreased slightly and then gradually reached a new equilibrium value (Fig. 6c). This can be explained by the fact that an increase in wind took more heat away from the dense region. From Fig. 6d and Fig. 6e, it can be seen that the increase of the primary air content had a big impact on the bed pressure difference and the height of the dense phase region. The increase of the primary air content made the bed materials leave the dense phase area. As a result, the bed pressure difference and the height of the dense phase region decreased. Figure 6f shows that a decrease in the combustion rate of coke occurred because particles were taken out of the dense phase zone. Although this process can promote combustion, the combustion rate was lower than before.

\section{CONCLUSIONS}

1. In the dense phase region of a $\mathrm{CFB}$, the selected parameters (e.g., bed temperature, pressure, and oxygen concentration) had a great influence on the flow characteristics, heat and mass transfer characteristics, chemical reactions, and pollutant removal efficiency of the whole bed. In this study, a mathematical model of a $130 \mathrm{t} / \mathrm{h}$ CFB boiler combustion system in the dense phase region was established on a MWorks simulation platform based on the Modelica language. The mathematical model adopted modular packaging to increase the universality of the model, and it used an implicit, high-order, and multi-step Dassl integration algorithm to conduct the simulation. Under the design condition parameters, the relative error between the bed temperature of the dense phase region obtained by the simulation model and the actual temperature was less than $3.8 \%$, which indicated that the static characteristics of the established simulation model were accurate.

2. A biomass feed step change test and a primary air volume step change test were conducted. The effect of biomass feed and primary air volume step changes on the bed temperature, oxygen content of the flue gas, height of the dense phase region, and the bed pressure difference in the dense phase region were investigated. It can be seen from the analysis that the temperature in the dense phase zone of the CFB increased when the biomass feed was increased. In contrast, the temperature in the dense phase zone of the CFB decreased when the primary air content was increased. Meanwhile, compared with the biomass feed, the primary air had a greater influence on the bed pressure difference and the height of the dense phase zone. 


\section{ACKNOWLEDGEMENTS}

The research was sponsored by National Natural Science Foundation of China (No. 51576040 and 51606113), National Key R\&D Program of China (No. 2019YFD1100602), Shandong Provincial Natural Science Foundation, China (No. ZR2019BEE049), and SDUT \& Zhoucun City Integration Development Project (No. 2020ZCXCZH09).

\section{REFERENCES CITED}

Alobaid, F., Mertens, N., Starkloff, R., Lanz, T., Heinze, C., and Epple, B. (2017). "Progress in dynamic simulation of thermal power plants," Prog. Energ. Combust. Sci. 59, 79-162. DOI: 10.1016/j.pecs.2016.11.001

Basu, P. (1990). "Heat transfer in high temperature fast fluidized beds," Chem. Eng. Sci. 45(10), 3123-3136. DOI: 10.1016/0009-2509(90)80058-M

Bergougnou, M. A., Briens, C. L., and Kunii, D. (1986). "Design aspects of industrial fluidized bed reactors. Research needs. Selected subjects," NATO ASI Seri.- Seri. E. 110, 305-347. DOI: 10.1007/978-94-009-4400-8_9

Bernhardt, D., and Beckmann, M. (2019). "Simplified process model for CFB combustion of different biomass as part of an assistance system for emission reduction," Fuel 250, 168-175. DOI: 10.1016/j.fuel.2019.02.017

Ceraolo, M., and Lutzemberger, G. (2019). "Use of Modelica language to simulate electrified railway lines and trains," Software-Pract. Exper. 49(7), 1114-1130. DOI: $10.1002 /$ spe. 2700

Chen, L., Wang, C. B., Shuai, T., and Edward, J. A. (2019). "Modelling the simultaneous calcination/sulfation behavior of limestone under circulating fluidized bed combustion conditions," Fuel 257, Article ID 116072. DOI: 10.1016/j.fuel.2019.116072

Eckert, E. R. G., and Martin, G. (1972). Analysis of Heat and Mass Transfer, McGrawHill, New York, NY, USA.

Geldart, D., and Baeyens, J. (1985). "The design of distributors for gas-fluidized beds," Powder Technol. 42(1), 67-78. DOI: 10.1016/0032-5910(85)80039-5

Gnanapragasam, N. V., and Reddy, B. V. (2009). "Numerical modeling of axial bed-towall heat transfer in a circulating fluidized bed combustor," Int. J. Heat Mass Tran. 52(7-8), 1657-1666. DOI: 10.1016/j.ijheatmasstransfer.2008.10.003

Gungor, A. (2008). "Two-dimensional biomass combustion modeling of CFB," Fuel 87(89), 1453-1468. DOI: 10.1016/j.fuel.2007.08.013

Koksharev, O., Gil, A. V., and Lebedev, V. M. (2017). “3D CFD simulation of aerodynamics of a 406 MWt CFB boiler," MATEC Web Conf. 110, Article ID 01041. DOI: $10.1051 /$ matecconf $/ 201711001041$

Kunii, D., and Levenspiel, O. (1990). "Fluidized reactor models. 1. For bubbling beds of fine, intermediate, and large particles. 2. For the lean phase. Freeboard and fast fluidization," Ind. Eng. Chem. Res. 29(7), 1226-1234. DOI: 10.1021/ie00103a022

Lu, B., Zhang, N., Wang, W., Li, J. H., Chiu, J. H., and Kang, S. G. (2013). “3-D full-loop simulation of an industrial-scale circulating fluidized-bed boiler," AIChE J. 59(4), 1108-1117. DOI: 10.1002/aic. 13917

Maccarini, A., Wetter, M., Afshari, A., Hultmark, G., Bergsoe, N. C., and Vorre, A. (2017). "Energy saving potential of a two-pipe system for simultaneous heating and 
cooling of office buildings," Energ. Build. 134, 234-247. DOI:

10.1016/j.enbuild.2016.10.051

Martin, H. (1984). "Heat transfer between gas fluidized beds of solid particles and the surfaces of immersed heat exchanger elements, Part II," Chem. Eng. Process. 18(4), 199-223. DOI: 10.1016/0255-2701(84)80005-7

Mikko, H., Oskar, K., and Emil, V. (2017). "Biomass combustion technology development - It is all about chemical details," P. Combust. Inst. 36(1), 113-134. DOI: $10.1016 /$ j.proci.2016.06.152

Ploch, T., Zhao, X., Hüser, J., Lieres, E. V., Hannemanntamas, R., Naumann, U., Wiechert, W., Mitso, A., and Noack, S. (2019). "Multiscale dynamic modeling and simulation of a biorefinery," Biotechnol. Bioeng. 116(10), 2561-2574. DOI: 10.1002/bit.27099

Qin, D. C., Li, J. J., Wang, T. T., and Zhang, D. M. (2019). "Modeling and simulating a battery for an electric vehicle based on Modelica," Auto. Innov. 2, 169-177. DOI: 10.1007/s42154-019-00066-0

Wang, H., Hu, C. H., He, J. P., Zhang, P., Xin, S. W., Gu, W., Du, J. J., Gu, C. Y., Wu, W. Z., Yang, B. Z., Xu, H. D., and Liu, J. H. (2019). "Research on heat absorption characteristics of high temperature heating surfaces of supercritical CFB boilers," IOP Conf. Seri.- Earth Environ. Sci. 227(4), Article ID 042060. DOI: 10.1088/1755$1315 / 227 / 4 / 042060$

Wang, Q., Xiao, J. B., and Liu, H. P. (2013). "CFD simulation of hydrodynamics on the dense region on a 65t/h oil shale-fired high-low bed CFB boiler," Powder Technol. 249, 339-352. DOI: 10.1016/j.powtec.2013.07.037

Wen, C. Y., and Chen, L. H. (1982) "Fluidized bed freeboard phenomena: Entrainment and elutriation," AIChE J. 28(1), 117-129. DOI: 10.1002/aic.690280117

Wen, C. Y., and Yu, Y. H. (1966). "A generalized method for predicting the minimum fluidization velocity," AIChE J. 12(3), 610-612. DOI: 10.1002/aic.690120343

Wu, H. C., Yang, C., He, H. X., Huang, S. L., and Chen, H. (2018). "A hybrid simulation of a 600 MW supercritical circulating fluidized bed boiler system," Appl. Therm. Eng. 143, 977-987. DOI: 10.1016/j.applthermaleng.2018.07.102

Xiao, H., Bai, J. B., Wu, Y. G., Wang, J. Q., Yang, X. H., and Zhang, G. F. (2009). "Dynamic simulation of a large scale $260 t / h$ CFB boiler based on SIMUCAD platform," in: 2009 ISECS International Colloquium on Computing, Communication, Control, and Management, IEEE, Sanya, China, pp. 246-249. DOI:

10.1109/CCCM.2009.5267720

Zhong, W. Q., Xie, J., Shao, Y. J., Liu, X. J., and Jin, B. S. (2015). “Three-dimensional modeling of olive cake combustion in CFB," Appl. Therm. Eng. 88, 322-333. DOI: 10.1016/j.applthermaleng.2014.10.086

Article submitted: April 24, 2020; Peer review completed: July 19, 2020; Revised version received and accepted: July 23, 2020; Published: August 10, 2020.

DOI: $10.15376 /$ biores.15.4.7443-7457 